\title{
Journalism
}

http://jou.sagepub.com/

\section{Hard and soft news: A review of concepts, operationalizations and key} findings

Carsten Reinemann, James Stanyer, Sebastian Scherr and Guido Legnante Journalism 2012 13: 221 originally published online 11 November 2011

DOI: $10.1177 / 1464884911427803$

The online version of this article can be found at:

http://jou.sagepub.com/content/13/2/221

Published by:

@SAGE

http://www.sagepublications.com

Additional services and information for Journalism can be found at:

Email Alerts: http://jou.sagepub.com/cgi/alerts

Subscriptions: http://jou.sagepub.com/subscriptions

Reprints: http://www.sagepub.com/journalsReprints.nav

Permissions: http://www.sagepub.com/journalsPermissions.nav

Citations: http://jou.sagepub.com/content/13/2/221.refs.html

>> Version of Record - Jan 11, 2012

OnlineFirst Version of Record - Nov 11, 2011

What is This? 


\title{
Hard and soft news: A review of concepts, operationalizations and key findings
}

Journalism

I3(2) 221-239

(c) The Author(s) 2011 Reprints and permission: sagepub. co.uk/journalsPermissions.nav DOI: |0.I I77/|4648849| |427803 jou.sagepub.com

\section{Carsten Reinemann}

Ludwig-Maximilians-University Munich, Germany

\section{James Stanyer}

Loughborough University, UK

\section{Sebastian Scherr}

Ludwig-Maximilians-University Munich, Germany

\section{Guido Legnante}

University of Pavia, Italy

\begin{abstract}
Over 30 years, a large body of research on what is often called 'hard' and 'soft news' has accumulated in communication studies. However, there is no consensus about what hard and soft news exactly is, or how it should be defined or measured. Moreover, the concept has not been clearly differentiated from or systematically related to concepts addressing very similar phenomena - tabloidization and 'infotainment'. Consequently, the results of various studies are hard to compare and different scientific discourses on related issues remain unconnected. Against this backdrop, this article offers a conceptual analysis of the concept based on studies in English and other languages. We identify key dimensions of the concept and make suggestions for a standardized definition and multi-dimensional measurement of harder and softer news. In doing so, we propose to distinguish thematic, focus and style features as basic dimensions that - in their combination - make up harder and softer types of news.
\end{abstract}

\section{Keywords}

conceptual analysis, content analysis, hard news, infotainment, soft news, tabloidization

\section{Corresponding author:}

Carsten Reinemann, Department of Communication Science and Media Research, Ludwig-MaximiliansUniversity, 80538 Munich, Germany

Email: reinemann@ifkw.Imu.de 


\section{Introduction}

Over 30 years, communication scholars have accumulated a large body of research on what is often called 'hard' and 'soft news' in English language publications. The terms have been used to classify both individual news reports and media formats. Very often, the use of these terms goes along with judgements about the quality of journalism and normative assumptions about media functions in democratic societies (e.g. Patterson, 2000; Zaller, 2003). In recent years, the dichotomy has become widely used for capturing developments of news coverage and current affairs media formats in the United States, various European countries and around the world. Besides investigating media content, scholars have addressed various related issues, such as how journalists classify different kinds of news (e.g. Lehman-Wilzig and Seletzky, 2010; Tuchman, 1973), why media makers turn from hard to soft news (e.g. Zelizer, 2004), how those forms of news are produced (Boczkowski, 2009), what their difference means from a feminist perspective (Lahva, 2009), and what effects hard and soft news has on audiences (Grabe et al., 2001; Patterson, 2000; Prior, 2003). These effects and their normative implications have been debated controversially (Patterson, 2000; Zaller, 2003).

However, in spite of the fact that most scholars seem to have an intuitive understanding of the concept and despite its ubiquity in the literature, scholars are far from reaching a consensus about how hard and soft news is to be defined. As Lahva (2009: 1) puts it: 'it is hard to think of other concepts that are so important and popular and at the same time so poorly defined and theorized' (see also Boczkowski, 2009; Lehman-Wilzig and Seletzky, 2010). What follows from this is that results of various studies are hard to compare and that different scientific discourses remain unconnected although they investigate very similar and important aspects of the changes news is going through around the globe.

Because of that, this article follows Sartori's (1984) early call for conceptual analyses in the social sciences. To do so, we first reflect on the theoretical and empirical foundations of the concept and discuss its conceptual definitions and dimensions. Our basis is a systematic analysis of the most important studies published since 1990 in both international English language and native language publications of 13 European countries. We put a special focus on studies either discussing the division of hard vs soft news theoretically or investigating it empirically by using content analysis. All studies were identified by searching journal article databases, university libraries, and various databases for chapters of edited books. Additionally, we used snowball sampling to identify relevant literature according to our criteria.

Because of the similarity of the two concepts we not only used 'hard news' and 'soft news' as search terms, but also included terms like 'infotainment' and 'tabloidization'. In sum, the sample of our literature analysis consists of 24 studies that were highly cited, that were especially comprehensive in their empirical investigation, or were especially thoughtful in their theoretical discussion of the concepts. After reviewing the conceptual foundations, we review some empirical findings of prior research and take a look at the operationalizations used in prior studies. Given the extent of collective ambiguity (Sartori, 1984) regarding the definition of the concept, we then make suggestions for a reconceptualization and for a standardized definition and measurement of harder and softer news items in quantitative content analysis. We are well aware that yet another 
definition might not seem useful at first sight. However, we want to propose a definition that reflects the multi-dimensionality which is already present in existing literature and that is less ambiguous as well as theoretically fruitful and empirically useful. By doing this and also providing suggestions for elements of a standard instrument, we want to facilitate collaborative, cumulative and comparative research that is currently hampered by a dramatic lack of conceptual consensus.

\section{Theoretical and empirical foundations}

The terms 'hard news' and 'soft news' are not scientific by origin. Although we do not exactly know when, the two terms were obviously first used by US journalists themselves to categorize different kinds of news. The terms then made their way step by step from journalistic into academic language. In the middle of the last century, Schramm (1949) was one of the first US scholars to reflect on the division between different types of news from the perspective of audiences. He distinguished between delayed-reward and immediate-reward news and his distinction very much resembles the division between hard and soft news. In addition, he discussed possible motives why people would choose those different kinds of news and what their effects could be (Schramm, 1949: 260-1). About 30 years later, in her widely cited study Tuchman (1973) addressed the issue from a journalists' perspective and investigated their understanding of 'hard news' and 'soft news'. Although Tuchman already stressed back then that journalists used the terms ambiguously, scholars began to use them more and more often to distinguish different kinds of news. The dichotomy became especially prominent in studies investigating 'the softening of news', 'tabloidization', or 'increasing infotainment'; that is, the changes to the content and style of news presentation (e.g. Connell, 1998; Donsbach and Büttner, 2005; Esser, 1999; Sparks, 2000; Uribe and Gunter, 2004). Those studies have contributed a lot to the fact that the hard vs soft dichotomy is widely used and therefore can be regarded as a key concept of political communication research.

\section{Conceptual definitions and dimensions}

\section{Definitions of hard vs soft news}

Despite the relevance of the potential softening of news, many authors comment that hard and soft news are often not clearly defined or not even defined at all (Baum, 2002: 92; Baum, 2003; Boczkowski and Peer, 2008; Lehman-Wilzig and Seletzky, 2010; Patterson, 2000). In fact, when reviewing the relevant studies, several problems become apparent. First, there actually is no consensus in the academic literature on the definition of hard and soft news. Second, the differences in definitions are fundamental and not negligible. Third, in most studies hard or soft news and similar terms are not used to describe single characteristics of news reports (e.g. its topic), but rather to describe a specific set of characteristics combined in news items. Fourth, authors having a multidimensional understanding of hard and soft news differ in the number and combination of dimensions they use and, to make matters worse, studies differ in the individual categories within those dimensions they regard as indicators for hard or soft news. Fifth, 
authors tend to stick to a uni-dimensional notion of hard and soft news even when they use several dimensions in their attempts to classify news.

To give an impression of the huge differences in definitions we want to give two examples. In the codebook to their internationally comparative study of news, Shoemaker and Cohen (2006) defined hard and soft news like this:

Hard news items are urgent occurrences that have to be reported right away because they become obsolete very quickly. These items are truly 'new' (...). Soft news items (...) are usually based on nonscheduled events. The reporter or media organization is under no pressure to publish the news at a certain date or time - soft news stories need not be 'timely'.

As can easily be seen, Shoemaker and Cohen's (2006) definition is quite straightforward because it just uses one single dimension to distinguish between hard and soft news - its topicality or timeliness. At the opposite end of a complexity continuum we find Patterson's definition:

Hard news refers to coverage of breaking events involving top leaders, major issues, or significant disruptions in the routines of daily life, such as an earthquake or airline disaster. Information about these events is presumably important to citizens' ability to understand and respond to the world of public affairs (...). Soft news (...) has been described (...) as news that typically is more personality-centered, less time-bound, more practical, and more incidentbased than other news (...). Finally, soft news has been described as a change in the vocabulary of news. The news is said to have become more personal and familiar in its form of presentation and less distant and institutional. (2000: $3-4)$

Although it is not easy to infer from this passage whether Patterson just refers to the understandings of others or his own, the categories he then uses to describe the softening of news clearly show the multi-dimensional character of his understanding. In fact, he refers to public policy components, sensationalism, human-interest elements, crimes and disasters as news subjects and the use of collectives and self-references as indicators of a softening of news. Other authors like Baum $(2002,2005,2007)$ also use this definition in their work.

Such a multi-dimensional approach, however, seems to be too complex and fuzzy for researchers who stick to just one dimension. However, a recent comparative study by Curran et al. (2010) illustrates the difficulties that researchers encounter when they try to use a seemingly easy and straightforward one-dimensional definition. In the study, hard news is defined as reports about politics, public administration, the economy, science, technology and related topics. Soft news is defined as reports about celebrities, human interest, sport and other entertainment-centred stories. Within the suggested crime category, however, the authors argue, it would be misleading to predetermine the hard or soft character of a report. Therefore they distinguish different types of crime news like this:

If a crime story was reported in a way that contextualized and linked the issue to the public good - for example, if the report referred to penal policies or to the general causes or consequences of crime - it was judged to be a hard news story assimilated to public affairs. If, however, the main focus of the report was the crime itself, with details concerning the 
perpetrators and victims, but with no reference to the larger context or implications for public policies, the news item was judged to be soft. (Curran et al., 2009: 9-10)

According to this qualification, it is not only the topic of a news item that makes it a 'hard' or 'soft' one, but also the framing of an event or topic linking it to the public good, to policy issues or to society at large. Obviously, topics here only serve as indicators for political or societal relevance. However, it seems questionable whether 'hard' topics necessarily contain such a relevance and 'soft' topics not. For example, a report about the market launch of a new cell phone does not seem to have too much relevance for the public good. On the other hand, celebrity news might indeed include references to important societal developments if, for example, celebrities advocate certain social issues. This means that a news item's topic and its linkage to the public good are two content dimensions that need to be conceptualized and measured separately. Whereas the topic dimension captures the subject matter, the linkage to the public will often depend on the focus or frame of a report. All in all, we are confronted with a situation of collective ambiguity (Sartori, 1984) that is first of all caused by homonymia: different authors use the same terms, but define them differently.

\section{Definitions of related concepts}

In addition to being defined in various ways by different authors the concept of hard vs soft news has also not been clearly differentiated or systematically related to other successful concepts addressing very similar phenomena. Most important in this respect are tabloidization, infotainment and sensationalism. In fact, the investigation of soft vs hard news is often quite similar or even part of research on those concepts (Baym, 2008; Bird, 2008). And, interestingly, criticism about conceptual fuzziness is as common with those concepts as it is with hard and soft news (Ban, 2008). A look at the definitions of all these concepts shows that they often largely overlap. Sometimes, the terms are seen alternately used to define each other. For example, a decreasing proportion of 'hard in respect to soft news' is one indicator in Uribe and Gunter's (2004: 390) definition of tabloidization. Baym (2008) describes infotainment as a term that 'is often used to denote the decline of hard news and public affairs discussion programs'. And Patterson (2000: 2-3) explains: " "Market-centered journalism" is one description of the tendency, "Infotainment" is another." "Soft news" (...) is a third.' Obviously, it is not only that the terms hard and soft news are used in varying meanings. Instead, other terms are used as synonyms to a certain extent. And this further contributes to the collective ambiguity of the concepts (Sartori, 1984).

\section{Dimensions of the concept}

In the literature reviewed we identified five dimensions used exclusively or in varying combinations to define hard vs soft news. These dimensions refer to different stages of the news production and reception process and also differ in the degree to which they are suitable for content analyses. The dimensions are (1) topic/events, (2) news production, (3) news focus, (4) news style and (5) news reception. Table 1 gives an overview of the 
dimensions used in the definitions of the most important, most cited and most comprehensive studies investigating hard and soft news. The table also includes some studies on tabloidization and sensationalism to show that they use very similar dimensions.

As Table 1 shows, only a quarter of the studies follow a one-dimensional approach to distinguish between hard and soft news - most of the studies use at least two dimensions. The most elaborate approach is presented by Baum (2002, 2003, 2007). He uses almost all dimensions that can be found in the literature. Most of the studies (83\%) use the topic dimension to identify or to differentiate between hard and soft news and at least half of the studies $(54 \%)$ use the style dimension, followed by characteristics of news production $(42 \%)$, a reception perspective $(29 \%)$ and news focus $(21 \%)$. What do those dimensions include?

As mentioned, most authors include (1) some characteristics of the topics or events covered. Definitions then refer to the subject matter of the topic or event (e.g. politics, economy, sports, culture). However, even here authors do not agree completely on what they regard as hard or soft topics (for an overview see De Swert, 2007). For example, whereas most definitions regard political affairs as a 'hard', they disagree on the status of disasters. Some regard them as hard (Patterson, 2000: 3), others as soft news (Schönbach, 2000: 65). The reason for this is that some authors (implicitly) have in mind other additional characteristics like timeliness and assume that certain topics have those characteristics in common. Some authors (2) use characteristics of the journalistic production process (for an overview see Boczkowski, 2009). For example, hard news is characterized as being timely, needing urgent dissemination or by the type of scheduling. Another group of authors takes (3) the focus of news reports into account. They look at what aspects of a topic or event are stressed. For example, thematic framing and the concentration on societal-level consequences of an event are regarded as indicators for hard news, whereas episodic framing and addressing the individual-level significance indicate soft news (Baum, 2002; Patterson, 2000).

A considerable number of authors also include (4) the style of news presentation. These characteristics do not refer to what is reported but how things are presented. For example, a factual, text-oriented style is regarded as indicating hard news, whereas a personalized, visually oriented style is regarded as indicative of soft news (Patterson, 2000). And finally, some authors also refer to (5) audience- or effect-related characteristics in their definitions. For example, soft news is described as more entertaining, interesting or personally useful, and hard news as being important, usually more interesting to men than women, or news that people should know when they want to understand public affairs.

Given the wide spectrum of dimensions used, it is remarkable that different types of news are still described by a dichotomy of hard and soft news in most studies. This is not to say that researchers have not begun to propose alternatives. For example, some authors suggest a scale with hard and soft news marking opposite ends of a continuum (Baum, 2007; also Brants, 1998, with respect to tabloidization) and some call for the inclusion of a third category between or in addition to hard and soft news. For example, Van Aelst and De Swert (2009) add 'sensational news' (accidents, disasters, crime) while Lehman-Wilzig and Seletzky (2010) suggest a 'general news' category. However, these authors also refrain from reflecting the multi-dimensional nature of news and formats in their definitions and 


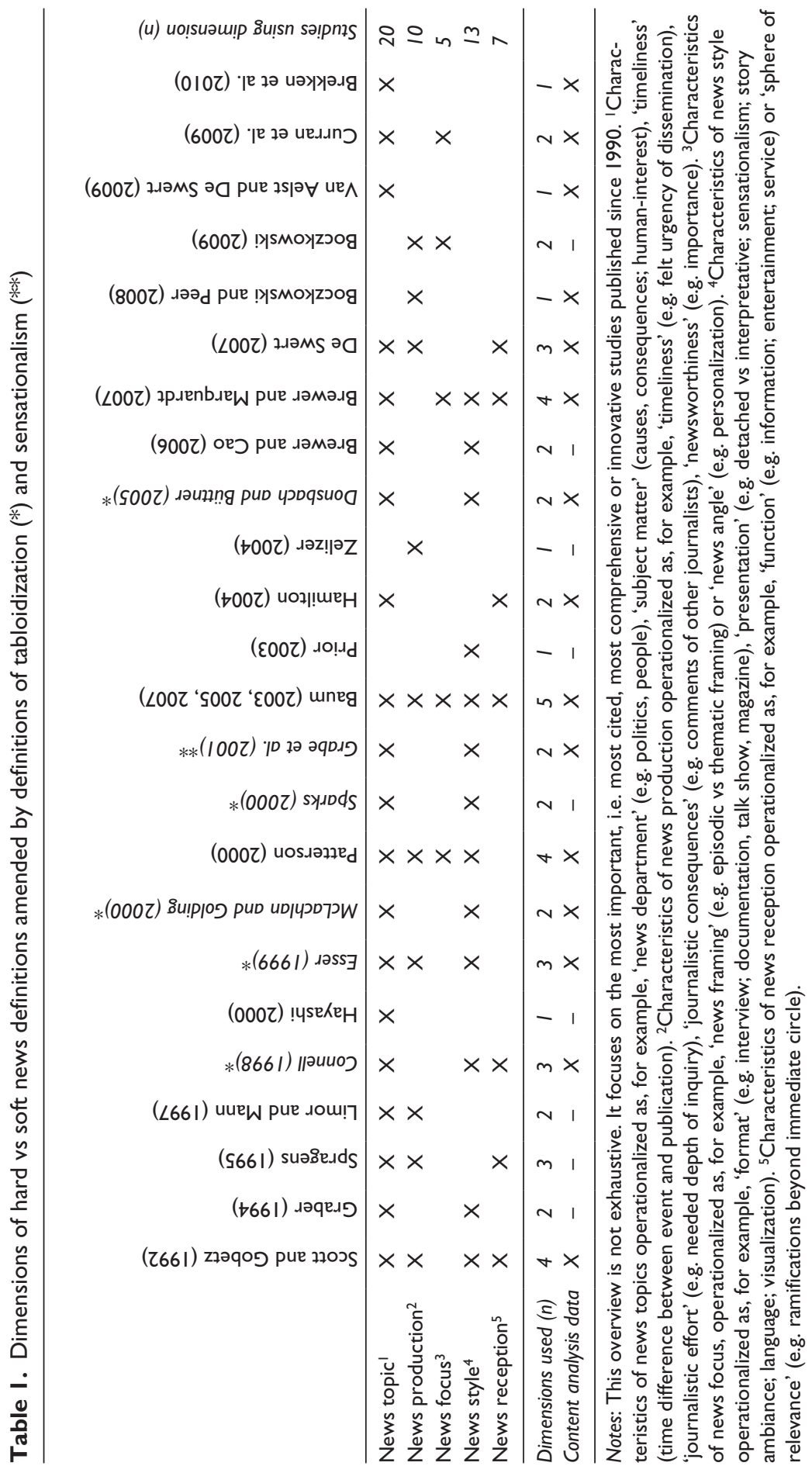


analyses, sometimes with reference to the widespread use of the terms 'hard' and 'soft' news. For example, Lehman-Wilzig and Seletzky (2010: 47) felt that 'at this stage' it was 'too great a leap to jump from two categories to a broad, semi-structured, multi layered spectrum' of criteria. But as the dimensional analysis shows, the common use of the terms overshadows fundamental conceptual differences. A lot of scholars talk about hard and soft news, but they very often have completely different things in their minds when doing so. Thus, the success of the terms obviously has become a major obstacle to conceptual clarification and development.

\section{Key findings}

The focus of the empirical studies we have reviewed includes TV network news, national and regional newspapers, and infotainment soft news shows, such as The Daily Show in the USA. With such a diverse focus and the conceptual differences that exist it comes as no surprise that results of research vary by country, by media and by the period under study. Although it is difficult to generalize them, most of the longitudinal studies seem to fall into three camps: those that have found that news is not becoming 'softer'; those that have found such evidence; and those that found mixed results for different media or content dimensions. In addition to reviewing some of those studies, we also want to give some information about the few comparative studies that exist.

\section{News is not becoming softer}

One of the most comprehensive studies of soft and hard television news has been by Scott and Gobetz (1992). They examined three national news networks in the USA from 1972 to 1987 . They found the amount of soft news per broadcast remained small by comparison to hard news. In Germany, Bruns and Marcinkowski's 1997 study focused on the number of political programs in different formats and times in four one-year periods. They found that there was an increasing amount of political information as a result of an increase of the number of stations and programs, and the development of $24 / 7$ programming. Waldahl et al. (2009) examined television news programs on the two main Norwegian channels in 1993, 2000 and 2007. They found that the majority of news output could be classified as hard news and the levels had not fallen over time. In terms of studies of newspapers, Allern (2001) examined news coverage in 10 Norwegian newspapers over one constructed week from 1998 to 1999. He found coverage was dominated by hard news topics. The tabloid press contained the most soft news, while national quality papers had the least, with the regional press falling in-between (2001). Schönbach's (2000) study focused on a week's output in the German regional press, comparing 350 newspapers in 1989 with 1994. The study found entertainment sections and entertaining news remained at the same level (1989 compared with the mid-1990s). Overall, there was not really more entertaining material and only a little more use of emotions. 


\section{News is becoming softer}

There have been a number of studies whose results have pointed towards the majority of news becoming softer over time. In his US study, Patterson (2000) investigated a sample of 5331 news items from two television networks, two weekly news magazines, three national and 26 local dailies between 1980 and 1999. On the aggregate level of all media, he found, for example, more news without a public policy component, more sensationalism, more human interest, and more human interest news, more self-references and less use of collectives. In Germany, Donsbach and Büttner (2005) looked for indicators of tabloidization and examined newscasts of the four main German television stations over four weeks before the national elections in 1983, 1990 and 1998. They found an overall reduction of political topics in three of the four newscasts. In addition, there was more drama, vividness, and visualization in three of the four newscasts. Sinardet et al. (2004) compared television news in the Dutch- and French-speaking parts of Belgium from 1 January 1993 to 31 December 2000. They found a lot of hard news had been replaced by soft news in the Dutch language channels but not in the French.

\section{Differences for media or content dimensions}

In contrast to the more or less clear-cut results of the studies mentioned above, many other studies do not fit into the picture of an across the board softening of news because they produced differing results for various media or different content dimensions. For example, Maier et al. (2009) examined German television newscasts on seven channels between 1992 and 2007. Their results show a difference between public service channels and their commercial rivals. Overall, while there was a linear increase of non-political content in commercial channels, this was not the case on public service channels. McLachlan and Golding (2000) examined four national UK newspapers, analysing one month's coverage at five-yearly intervals between the 1950s and the 1990s. They found that in the Sun and the Mirror entertainment news stories increased while human interest stories remained stable over time. Political stories also increased but much less significantly. In The Times and the Guardian there was more fluctuation in entertainment and human interest news stories while political stories remained fairly constant. Also focusing on the UK press, Uribe and Gunter (2004) found that coverage in the tabloids could be characterized as 'soft' dominated by home stories, with a significant presence of headlines and visuals and a personalized angle of coverage. Between 1991 and 2001, tabloid news became more 'tabloidized' in its form and style, but remained constant in its range of contents.

This distinction between style and content in tabloid outlets also surfaces in US studies of so-called 'soft news shows'. These studies have challenged the perception that such shows are devoid of political content. For example, Brewer and Marquardt (2007) examined the amount of 'political news' on soft news shows. Their content analysis of the 52 new episodes of The Daily Show in 2005 found that The Daily Show often focused on international stories that could be told through 'cheap framing' - that is, in simple and entertaining ways. This difference between content dimensions is also apparent in a study by Boczkowski and Peer (2008). In the USA they analysed three composite weeks 
of online news output in 2007. The study sought to distinguish between softening in terms of what stories are told and how they are told, and tried to disentangle the influence of journalists' and consumers' choices on each other. They found that journalists' supply of news is markedly 'soft' in terms of what stories are told but not regarding how they are told.

\section{Internationally comparative studies}

There have been few comparative studies of hard and soft news. Perhaps one of the most comprehensive comparative studies of hard and soft news has been Brekken et al.'s study of press and broadcast news output in six democracies, which was part of a wider study on how media inform democracies (2010; see also Curran et al., 2009, 2010). They examined three non-consecutive weeks' news output in 2008 and 2009 in Belgium, the Netherlands, Norway, Sweden, the UK and the USA; a total of 21 days were sampled. In total two television channels (at least one was PBS) and three newspapers were investigated (a quality paper, a tabloid and a regional paper). The study found that across different media types and countries hard news was not significantly lower in the UK and the USA compared to the others, and the differences between commercial TV and public broadcasting in Europe did not seem to be especially large (Curran et al., 2010). In terms of newspapers, the study found that tabloid newspapers did not present as much hard news as elite newspapers do. Contrary to expectation, the study found that the American TV channels actually offer the highest degree of hard news as compared to the other countries.

In contrast, the aforementioned study of Curran et al. (2009), which was set up in a similar way to Brekken et al. (2010), brought some different results to light. Interestingly, the authors are pointing to coding problems when crimes had to be judged (Curran et al., 2009: 9-10). In general and surprisingly, there is more hard than soft news in both television and newspapers in all countries. These results include the observation that, unlike Brekken at al. (2010), the US news is overall (both newspapers and television) 'harder' than expected. Some similarities between the countries presented here must be critically discussed however. According to this research, US and UK television are similar in their affinity to hard news, even though the UK has a strong PBS and the USA do not. Therefore, the question arises whether this is the result of coding ambiguities. Intercoder reliability yielded an agreement of more than 80 per cent in the European countries of the sample and ranged, in contrast, between 72 per cent and 91 per cent in the USA. Unfortunately, the study indicates no cross-national reliability coefficients.

\section{Operationalizations}

Given the variety of definitions it is not feasible to give a comprehensive overview of the diverse operationalizations used in content analyses to identify hard and soft news. Moreover, information about operationalizations is often completely missing. In addition, authors hardly try to measure production- and effects-related characteristics in content analyses although these dimensions may be important parts of their definitions of hard and soft news. The reason for this is that these features are hard to 
infer from news reports themselves. In order to measure them, surveys of journalists, participant observations in newsrooms or effects studies including ordinary recipients would be needed. And because our focus here is on characteristics measurable in actual news content, we concentrate solely on the topic, focus and style dimensions to give an impression of how hard and soft news has been measured in content analysis.

As far as the topics/events dimension is concerned, most authors use the main topics of an item as an indicator. We have stated that there are at least some differences in what topics are assigned to hard vs soft news and that there are authors who add a third category (Lehman-Wilzig and Seletzky, 2010; Van Aelst and De Swert, 2009). The length and structure of the topic lists also varies considerably, but, mostly, quite broad categories are used. Foreign and domestic politics, economy and finance are usually regarded as hard news. News about sports, celebrities, royal families, crime, scandals and service are regarded as soft news (De Swert, 2007). In addition, studies differ on whether they code only one (Scott and Gobetz, 1992) or several (Brewer and Marquardt, 2007) topics per news item. Other authors code specific policy issues in addition to more general topics (Patterson, 2000). Again, other authors also take into account the presence of certain actors (De Swert, 2007). Unfortunately, it often remains unclear exactly why certain topics are regarded as hard or soft. Going through the literature it seems, however, that most authors use topics only as substitute indictors for other characteristics representing the real cause for categorizing an item as hard or soft. For example, authors often seem to have in mind the societal relevance or informational/entertaining value of an item and make the implicit assumption that items sharing the same topic are also similar in this respect. However, assigning certain topics to the hard and soft category in advance may be misleading because seemingly soft topics may be framed as socially relevant or hard news might be presented as light-hearted, entertaining and with a focus on their 'soft' aspects.

Regarding the focus dimension, studies point to the fact that the same topic or event can be looked at from various perspectives. Patterson (2000) is one of those authors to include various categories relating more to the focus dimension of stories. For example, he distinguishes whether reports use a public vs private frame, whether they apply a policy- or non-policy frame, whether they give 'news you can use', whether the contextual frame is either episodic or thematic and whether a human interest frame is used. The linkage to the public good is also apparent in the works by Baum $(2002,2005,2007)$ and Curran et al. (2009).

And finally, as far as the style dimension is concerned, a close look at operationalizations reveals that the concrete indicators used relate to two different sub-dimensions of style. One group of indicators measures whether journalists' subjective impressions or opinions are apparent in a report. For example, authors look at whether a report presents facts in a detached way or whether it is news analysis, feature style or commentary giving the personal author's point of view (Boczkowski and Peer, 2008; Patterson, 2000). A second group of indicators refers to story ambiance (serious vs light-hearted; Patterson, 2000), a sensational presentation which describes events as 'earthshaking/ unsettling/remarkable' (Patterson, 2000: 26) or a more informal and colloquial vocabulary. 


\section{Towards conceptual clarity}

As always in the social sciences there is no 'true' or 'false' definition of a concept. Rather, definitions of concepts can be more or less precise, unambiguous, theoretically fruitful and empirically useful (Opp, 2005; Sartori, 1984). Given the high degree of collective ambiguity regarding the understanding of hard vs soft news we want to suggest a standardized definition and measurement that also reflects the multi-dimensional character of different types of news that is apparent in many of the studies reviewed here.

To develop our definition, we revert to the literature and the dimensions collected from there. What we found first was that the interest in hard vs soft news is mainly stirred by the assumption that the changing nature of news might have an effect on politically and/or socially relevant perceptions of audiences. In line with this basic consensus, we propose to distinguish harder and softer forms of news with respect to message elements that potentially have an impact on perceptions of public affairs. This does not imply that we have a preference for a specific way of news reporting; for example, a traditional, non-entertaining or strictly text-based style. It does mean, however, that we (a) regard the reporting of politically relevant issues as a core responsibility of journalism, and that we (b) consider the investigation of the intensity and character of this reporting a central topic of journalism research.

A second consistent pattern in most content analysis is that production and effectsrelated characteristics are not directly measured - although sometimes included in definitions. One reason for this is that these are not characteristics of content itself and therefore hard to code without severe problems of reliability. Therefore, we also focus on characteristics of content itself. This does mean, of course, that we completely break with prior journalistic usage and one of its major ingredients - timeliness. Besides the fact that timeliness is not a content characteristic there is another reason for not including it here: the relation between the timeliness of stories and political perceptions of recipients is completely unclear. For example, background or investigative stories may be highly politically relevant although they are not triggered by events that happened yesterday. Therefore, coding the time difference between event and reporting as apparent in a news item itself does not seem to tell a lot.

A third consistent idea in the literature is that softer and harder news can be the result of the selection of specific events, the specific aspects focused on or the way they are presented. In line with this, we also include those three kinds of content dimensions. And finally, a fourth notion that has become prominent in recent years is that it is not fruitful to stick to a dichotomy of hard vs soft news but rather to think of a continuum or of different clusters of news items based on multiple content dimensions.

Against this backdrop we propose to distinguish harder and softer news based on three dimensions: (1) The subject matter covered (topic dimension), (2) the specific aspects of events or topics emphasized (focus dimension), and (3) the way events or topics are visually and verbally presented (style dimension). However, although conceptualizing hard vs soft news multi-dimensionally, we would suggest that the topic dimension is the foundation on which the focus and style dimension are grounded. We would argue that a news item reporting a politically relevant event will always be 'harder' than a politically irrelevant item - even if the focus and style are 'softer' for the first and 'harder' for the latter item. 
Within the three dimensions, further distinctions are necessary. In the topic dimension we propose to distinguish different degrees of political relevance. In contrast to most other studies, however, we do not propose a list of broad topic categories that are often supposed to indicate the political or societal relevance of a news item. Instead, following Bruns and Marcinkowski (1997), we define the degree of political relevance as indicating the extent to which the content of a news item deals with norms, goals, interests, and activities related to the preparation, assertion, and implementation of authoritative, generally binding decisions about societal conflicts. To measure the political relevance of a news item we propose four indicators detailed in the Appendix. They refer to the mentioning of societal actors, of decision-making authorities, of a proposed plan or program, and of the people concerned by a decision. The more aspects are mentioned, the higher the degree of political relevance of a news item. Using these indicators also means that an actor and public policy perspective is included in the topic dimension. On that dimension, the softening of news could mean that the degree of political relevance is reduced.

Regarding the focus dimension we propose to first distinguish between reports stressing the public or social relevance or consequences of an event and reports stressing personal or private aspects and consequences. In addition, news reports can be differentiated insofar as they use thematic or episodic framing. On that dimension, the softening of news could be indicated by an increasing focus on personal and private matters or on single events and exemplars.

Regarding the style dimension we propose to first differentiate between reports that include explicit expressions of journalists' personal impressions, interpretations or opinions and others that do not include such personal views. In addition, we distinguish between reports that include verbal and/or visual emotion-arousing elements and reports that do not include such elements. The softening of news on this dimension could be indicated by a more personal or more emotional style.

Based on the three dimensions and having in mind the categories we propose we then would define harder and softer news as follows:

The more a news item is politically relevant, the more it reports in a thematic way, focuses on the societal consequences of events, is impersonal and unemotional in its style, the more it can be regarded as hard news. The more a news items is not politically relevant, the more it reports in an episodic way, focuses on individual consequences of events, is personal and emotional in style, the more it can be regarded as soft news.

The dimensions and categories we suggest can be used individually or all at one time. In addition to the coding of individual news items, news formats, programmes or outlets can be categorized as being harder or softer when aggregating the results of the individual news items' coding. Using the dimensions and categories we suggest will allow for the construction of a simple additive index representing the position of a news item on a continuum from harder to softer types of news. This analytical approach would be more in line with the traditional notion of a hard vs soft dichotomy. The full potential of our approach, however, will be utilized if the dimensions are analysed in combination with each other, for example, by using cluster analysis. This would allow for the construction of clusters of news items representing varying combinations of dimensions and categories. This approach would be more in line with a multi-dimensional notion of different types of news. 
Table 2. Dimensions and possible categories for measuring harder and softer news in content analysis studies

\section{Topic dimension}

politically relevant not politically relevant

\section{Focus dimension}

societal - individual relevance thematic - episodic framing

\section{Style dimension}

impersonal - personal reporting unemotional - emotional reporting

To conceptualize hard and soft news the way we suggest has several advantages. First, taking into account the multi-dimensional character of news will allow for more sophisticated and fine-grained analyses of the structure of news. Second, going beyond single dimensions will likely be helpful when combining content analyses with uses and effects studies. Third, in contrast to solely concentrating on the topic dimension, the inclusion of the focus and style dimensions allows for capturing relevant changes of the structure of news below the level of the news agenda. This is especially important given the abovementioned results of studies that surfaced differing findings for the topics and the style dimension (Baum, 2002; Bruns and Marcinkowski, 1997; Graber, 1994). Fourth, including the focus dimension is especially important both against the backdrop of research on news formats of current affairs presentation (Baum, 2005) and given the impressive literature showing the importance of framing for the perception of news (Aalberg et al. in this special issue). Fifth, in contrast to solely relying on subject and focus the style dimension enables researchers to incorporate concepts like emotionalization that are regarded as important means of getting audience attention and that are also likely to have an impact on audience perceptions (Table 2).

\section{Towards increasing comparability and cumulativity}

We are well aware that some readers will not find their idea of hard and soft news represented in the concept we propose. Some may want to stick to an easier concept, solely focusing on one dimension or category. Some may want to exclude one dimension or another because they feel that some dimension or another makes up a concept of its own. However, as the literature review has shown, the terms hard and soft are used by most authors for describing a whole set of characteristics represented in individual news items. And taking this seriously results in a set of indicators that very much resembles the indicators used in research on tabloidization and infotainment. And we would therefore suggest using the 'softening of news', 'tabloidization' and 'growing infotainment' as synonyms. Based on this set of indicators proposed here, clusters of similar news items can be described and different clusters can be identified for different media systems and countries. The sizes of the clusters and their development over time would give us a much more nuanced and informative view of what has evolved and is still changing in current affairs journalism across the globe, compared to studies that use single indicators that are usually analysed one by another. Using commonly shared concepts, definitions and operationalizations would help to increase comparability and contribute to a more effective accumulation of knowledge. 


\section{References}

Allern S (2001) Nyhetsverdier [News values]. Kristiansand: IJ forlaget.

Ban H (2008) Soft news. In: Donsbach W (ed.) The International Encyclopedia of Communication. London: Blackwell. Available at: www.communicationencyclopedia.com

Baum MA (2002) Sex, lies, and war: How soft news brings foreign policy to the inattentive public. American Political Science Review 96(1): 91-109.

Baum MA (2003) Soft News Goes to War: Public Opinion and American Foreign Policy in the New Media Age. Princeton, NJ: Princeton University Press.

Baum MA (2005) Talking the vote: Why presidential candidates hit the talk show circuit. American Journal of Political Science 49(2): 213-234.

Baum MA (2007) Soft news and foreign policy: How expanding the audience changes the policies. Japanese Journal of Political Science 8(1): 115-145.

Baym G (2008) Infotainment. In: Donsbach W (ed.) The International Encyclopedia of Communication. London: Blackwell. Available at: www.communicationencyclopedia.com

Bird SE (2008) Tabloidization. In: Donsbach W (ed.) The International Encyclopedia of Communication. London: Blackwell. Available at: www.communicationencyclopedia.com

Boczkowski PJ (2009) Rethinking hard and soft news production: From common ground to divergent paths. Journal of Communication 59(1): 98-116.

Boczkowski PJ and Peer L (2008) The choice gap: The softening of news and the divergent preferences of journalists and consumers. 58th Annual Conference of the International Communication Association, Montreal, 22-26 May 2008. Montreal: ICA.

Brants K (1998) Who's afraid of infotainment? European Journal of Communication 13(3): 315335.

Brekken T, Thorbjørnsrud K and Aalberg T (2010) Media systems and political information resources: An empirical study of focus and frames across countries and news media outlets. American Political Science Association Annual Meeting, Washington, DC, 2-5 September 2010. Washington, DC: APSA.

Brewer PR and Cao X (2006) Candidate appearances on soft news shows and public knowledge about primary campaigns. Journal of Broadcasting and Electronic Media 50(1): 18-35.

Brewer PR and Marquardt E (2007) Mock news and democracy: Analyzing The Daily Show. Atlantic Journal of Communication 15(4): 249-267.

Bruns T and Marcinkowski F (1997) Politische Information im Fernsehen: Eine Längsschnittstudie zur Veränderung der Politikvermittlung in Nachrichten und politischen Informationssendungen [Political information in television: A longitudinal study of changes in political content in news and information programs]. Opladen: Leske + Budrich.

Connell I (1998) Mistaken identities: Tabloid and broadsheet news discourse. Javnost - The Public 5(3): 11-31.

Curran J, Iyengar S, Lund AB and Salovaara-Moring I (2009) Media system, public knowledge and democracy: A comparative study. European Journal of Communication 24(1): 5-26.

Curran J, Salovaara-Moring I, Cohen S and Iyengar S (2010) Crime, foreigners and hard news: A cross-national comparison of reporting and public perception. Journalism 11(1): 3-19.

De Swert K (2007) Soft en hard nieuws als kwaliteitskenmerk van het televisienieuws [Soft and hard news as quality criteria for television news]. In: Hooghe M, De Swert K and Walgrave S (eds) De kwaliteit van het nieuws: Kwaliteitsindicatoren voor televisienieuws [The quality of news: Quality criteria for television news]. Leuven: Acco, 131-149.

Donsbach W and Büttner K (2005) Boulevardisierungstrend in deutschen Fernsehnachrichten. Publizistik 50(1): 21-38.

Esser F (1999) Tabloidization of news. European Journal of Communication 14(3): 291-324.

Grabe ME, Zhou S and Barnett B (2001) Explicating sensationalism in television news: Content and the bells and whistles of form. Journal of Broadcasting and Electronic Media 45(4): 635-655. 
Graber DA (1994) The infotainment quotient in routine television news: A director's perspective. Discourse and Society 5(4): 483-508.

Hamilton JT (2004) All the News That's Fit to Sell: How the Market Transforms Information into News. Princeton, NJ: Princeton University Press.

Hayashi K (1998) The 'Home and Family' section in the Japanese newspaper. In: Sparks C and Tulloch J (eds) Tabloid Tales: Global Debates over Media Standards. Lanham, MD: Rowman and Littlefield, 147-162.

Lahva H (2009) 'Hard' news, 'soft' news and the gendered discourse of 'important' and 'interesting'. 57th Annual meeting of the International Communication Association, Chicago, IL, 21-25 May 2009. Chicago, IL: ICA.

Lehman-Wilzig SN and Seletzky M (2010) Hard news, soft news, 'general' news: The necessity and utility of an intermediate classification. Journalism 11(1): 37-56.

Limor Y and Mann R (1997) Itona 'ut [Journalism]. Tel Aviv: Open University.

McLachlan S and Golding P (2000) Tabloidization in the British press: A quantitative investigation into changes in British newspapers, 1952-1997. In: Sparks C and Tulloch J (eds) Tabloid Tales: Global Debates over Media Standards. Lanham, MD: Rowman and Littlefield, 76-90.

Maier M, Ruhrmann G and Stengel K (2009) Der Wert von Nachrichten im deutschen Fernsehen: Inhaltsanalyse von TV-Nachrichten im Jahr 2007 [News values in German TV: A content analysis of TV news in 2007]. Düsseldorf: Landesanstalt für Medien.

Opp K-D (2005) Methodologie der Sozialwissenschaften: Einführung in die Probleme ihrer Theorienbildung und praktischen Anwendung [Methodology in the social sciences: Introduction to problems in theory building and its application]. Wiesbaden: VS-Verlag.

Patterson TE (2000) Doing Well and Doing Good: How Soft News Are Shrinking the News Audience and Weakening Democracy. Cambridge, MA: Harvard University Press.

Prior M (2003) Any good news in soft news? The impact of soft news preference on political knowledge. Political Communication 20(2): 149-171.

Sartori G (1984) Guidelines for concept analysis. In: Sartori G (ed.) Social Science Concepts: A Systematic Analysis. Beverly Hills, CA: SAGE, 15-85.

Schönbach K (2000) Does tabloidization make German local newspapers successful? In: Sparks C and Tulloch J (eds) Tabloid Tales: Global Debates over Media Standards. Lanham, MD: Rowman and Littlefield, 63-74.

Schramm W (1949) The nature of news. Journalism Quarterly 26: 259-269.

Scott DK and Gobetz RH (1992) Hard news/soft news content of the national broadcast networks, 1972-1987. Journalism Quarterly 69(2): 406-412.

Shoemaker PJ and Cohen AA (2006) News around the World. Content, Practitioners, and the Public. New York: Routledge. [Codebook available from the authors]

Sinardet D, De Swert K and Dandoy R (2004) Franstalig, Vlaams, commercieel, openbaar: zoek de verschillen: een longitudinale vergelijking van de thema's in de Belgische televisiejournaals [French, Flemish, commercial, public: Find the differences. A longitudinal comparison of topics in Belgian television news]. Antwerpen: UA, Faculteit Politieke en Sociale Wetenschappen.

Sparks C (2000) Introduction: Panic over tabloid news. In: Sparks C and Tulloch J (eds) Tabloid Tales: Global Debates over Media Standards. Lanham, MD: Rowman and Littlefield, 1-40.

Spragens WC (1995) Electronic Magazines: Soft News Programs on Network Television. Westport, CT: Praeger.

Tuchman G (1973) Making news by doing work: Routinizing the unexpected. The American Journal of Sociology 79(1): 110-131.

Uribe R and Gunter B (2004) Research note: The tabloidization of British tabloids. European Journal of Communication 19(3): 387-402. 
Van Aelst P and De Swert K (2009) Politics in the news: Do campaigns matter? A comparison of political news during election periods and routine periods in Flanders (Belgium). Communications 34: 149-168.

Waldahl R, Andersen MB and Rønning H (2009) TV-nyhetenes verden [The world of television news]. Oslo: Universitetsforlaget.

Zaller J (2003) A new standard of news quality: Burglar alarms for the monitorial citizen. Political Communication 20(2): 109-130.

Zelizer B (2004) Taking Journalism Seriously: News and the Academy. Thousand Oaks, CA: SAGE.

\section{Appendix.}

\section{Coding instructions}

Topic dimension:

Political relevance

$(I-4)$
Focus dimension I: Individual - Societal Relevance
Here, the political relevance of a news item is coded. It indicates the extent to which the content of a news item deals with norms, goals, interests and activities related to the preparation, assertion, and implementation of authoritative, generally binding decisions about societal issues. Four aspects are distinguished that indicate the degree of political relevance of a news item: (I) societal actors, (2) decision-making authorities, (3) policy plan and (4) actors concerned. For each of those aspects the presence $(I)$ or non-presence $(0)$ is coded.

(I) Two or more societal actors that disagree on a societal issue (e.g., two parties, a party and an NGO, voters and politicians, employers and trade unions).

$0=$ not present; $\mathrm{I}=$ present

(2) Decision-making authorities (legislative, executive, judiciary) that are or could be involved in the generally binding decision about that societal issue.

$0=$ not present; $\mathrm{I}=$ present

(3) The substance of a planned or realized decision, measure, programme that relates to the issue.

$0=$ not present; $I=$ present

(4) The persons or groups concerned by the planned or realized decisions, measures, programmes.

$0=$ not present; $I$ = present

Here, the focus of a news item as related to the accentuation of personal or societal relevance is coded. Individually focused news stress the personal, private meaning or consequences of the incidents, developments, decisions etc. reported about for members of society. In contrast to that, socially focused news stress the general, overall meaning or consequences of the incidents, developments, decisions etc. reported about for society at large. For example, a report on measures against climate change might either stress that everybody will have to pay more for electricity (individual relevance) or that industrial societies will have to change their ways of energy production (societal relevance). The middle category is to be chosen if about equal attention is given to both aspects. 


\section{Appendix. (continued)}

Coding instructions

Focus dimension 2:

Episodic - Thematic Framing

$0=$ pure or predominant focus on individual relevance $/$ consequences

I = mixed attention to individual and societal relevance /

consequences

2 = pure or predominant focus on societal relevance / consequences

Here, the focus of a news item as related to the accentuation of episodes or themes is coded. Episodically focused news items present an issue by offering a specific example, case study, or event oriented report, e.g., covering unemployment by presenting a story on the plight of a particular unemployed person. Thematically focused news items place issues into a broader context, e.g., covering unemployment by reporting on the latest unemployment figures and offering commentary by economists or public officials on the impact of the economy on unemployment. The middle category is to be chosen if about equal attention is given to both aspects.

$0=$ pure or predominant episodic framing

$\mathrm{I}=$ mixed episodic and thematic framing

$2=$ pure or predominant thematic framing

Style dimension I: Personal Impersonal Reporting

Style dimension 2: Emotional Unemotional Reporting
Here, the journalistic style of a news item as related to the explicit appearance of journalists' personal points of view is concerned. It is coded whether a news item includes explicit statements of the reporting journalists' personal impressions, interpretations, points of view or opinions. Journalists not being the authors of the news item (and who may be cited as experts, for example) are not taken into account here. The middle category is to be chosen if personal and impersonal elements are mixed.

$0=$ purely or predominantly personal

$\mathrm{I}=$ mix of personal and impersonal elements

2 = purely or predominantly impersonal

Here, the journalistic style of a news item as related to the emotional presentation of information is coded. This category does not relate to the emotion-arousing potential of the topic, event etc. itself that is covered in a news report. Emotional news items use verbal, visual or auditive means that potentially arouse or amplify emotions among audience members. This can be done, for example, (a) by dramatizing events, i.e. presenting them as exceptional, exciting, or thrilling; (b) by affective wording and speech, e.g. superlatives, strong adjectives, present tense in the description of past events, pronounced accentuation; (c) by reporting on or visually presenting explicit expressions of emotions (e.g., hurt, anger, fear, distress, joy). Unemotional news present their information in a matter-of-fact style not using emotionally arousing verbal, visual or auditive means. The middle category is to be chosen if emotional and unemotional elements are mixed.

$0=$ purely or predominantly emotional

$\mathrm{I}=$ mix of emotional and unemotional elements

$2=$ purely or predominantly unemotional 


\section{Biographical notes}

Carsten Reinemann is a Professor of Political Communication at the Department of Communication Science and Media Research, Ludwig-Maximilians-University Munich, Germany.

James Stanyer is a Senior Lecturer in Media and Communication Studies at the Department of Social Sciences, University of Loughborough, UK.

Sebastian Scherr is a Research Assistant at the Department of Communication Science and Media Research, Ludwig-Maximilians-University Munich, Germany.

Guido Legnante is an Associate Professor of Political Science at the Department of Political and Social Studies at the University of Pavia, Italy. 